\title{
PELATIHAN PENYUSUNAN PERANGKAT PEMBELAJARAN SAINS KIMIA BERBASIS BUDAYA BALI BAGI GURU-GURU IPA SMP DI KECAMATAN SUKASADA
}

\author{
I Nyoman Suardana, I Dewa Ketut Sastrawidana, dan Nyoman Retug \\ Fakultas Matematika dan IPA \\ Universitas Pendidikan Ganesha
}

\begin{abstract}
ABSTRAK
Guru sebagai pendidik profesional seharusnya memiliki kemampuan merancang dan melaksanakan pembelajaran yang menarik dan bermakna sehingga protensi diri peserta didik dapat dikembangkan secara optimal. Pengembangan pembelajaran berbasis budaya Bali merupakan salah satu alternatif yang dapat dilakukan. Namun, guru-guru IPA SMP di Kecamatan Sukasada belum memiliki pemahaman tentang pembelajaran berbasis budaya Bali. Dengan demikian, kegiatan P2M ini bertujuan untuk meningkatkan pemahaman guru-guru IPA SMP di Kecamatan Sukasada tentang pembelajaran berbasis budaya Bali. Kegiatan P2M ini dilakukan melalui seminar dan pelatihan penyusunan perangkat pembelajaran sains kimia berbasis budaya Bali. Sasaran kegiatan ini adalah guru-guru IPA SMP di Kecamatan Sukasada. Seminar dan pelatihan dilaksanakan pada Rabu, 6 Nopember 2013 bertempat di Ruang Sidang FMIPA UNDIKSHA. Guru IPA SMP yang hadir dalam kegiatan tersebut sebanyak 8 orang dari jumlah keseluruhan undangan 24 guru. Hasil dari kegiatan tersebut adalah sebagai berikut. 1) Kegiatan P2M dapat meningkatkan pemahaman guru-guru IPA SMP di Kecamatan Sukasada tentang budaya Bali yang relevan dengan sains kimia SMP dan pembelajaran berbasis budaya Bali. 2) Kegiatan P2M dapat meningkatkan pemahaman dan keterampilan guru-guru IPA SMP dalam penyusunan perangkat pembelajaran sains kimia berbasis budaya Bali. 3) Kegiatan P2M mendapat respon positif dari guru-guru yang terlibat dalam seminar dan pelatihan penyusunan perangkat pembelajaran sains kimia berbasis budaya Bali.
\end{abstract}

Kata-kata kunci: pembelajaran sains kimia, budaya Bali, guru IPA SMP, Sukasada

\begin{abstract}
Teacher as professional educator should have ability to design and conduct interesting and meaningful teaching and learning so student's pontensial can be developed optimally. Developing of teaching and learning based on Baliness culture is an alternative can be conducted. However, science teachers of secondary school in Sukasada sub-dictrict not have understanding about it. Thereby, this devotion to sosiety aimed to improve science teachers of secondary school in Sukasada sub-dictrict about teaching and learning based on Baliness culture. This devotion to sosiety activities was conducted by seminar and training about designing of teaching and learning based on Baliness culture tools of chemistry science. The target of this activity was science teachers of secondary school in Sukasada sub-dictrict. Seminar and training were conducted on Wednesday, November $6^{\text {th }} 2013$ in Assembly Room of FMIPA
\end{abstract}


UNDIKSHA. There were eight science teachers of secondary school that attend in this activity from 24 teachers that were invited. The results of these activities were as follows. 1) Devotion to sosiety activities could improve understanding of science teachers of secondary school in Sukasada sub-dictrict about Baliness culture that have relevance to chemistry science and teaching and learning based on Baliness culture. 2) Devotion to sosiety activities could improve understanding and skills of science teachers of secondary school in Sukasada sub-dictrict in designing of teaching and learning based on Baliness culture tools of chemistry science. 3) Devotion to sosiety activities got positive respons from teachers who participated in seminar and training about designing of teaching and learning based on Baliness culture tools of chemistry science.

Keywords: teaching and learning of chemistry science, Baliness culture, science teachers of secondary school, sukasada

\section{Pendahuluan}

Kecamatan Sukasada merupakan salah satu kecamatan dari sembilan kecamatan yang terdapat di Kabupaten Buleleng. Kecamatan Sukasada terdiri atas dua belas desa pekraman, yaitu: Desa Kayu Putih, Desa Padang Bulia, Desa Pancasari, Desa Panji Anom, Desa Panji, Desa Sambangan, Desa Selat, Desa Silangjana, Desa Tegal Linggah, Desa Wanagiri, Desa Pegadungan, dan Desa Pegayaman. Di Kecamatan Sukasada terdapat delapan Sekolah Menengah Pertama (SMP/Mts.), yaitu SMP Negeri 1 Sukasada, SMP Negeri 2 Sukasada, SMP Negeri 3 Sukasada, SMP Negeri 4 Sukasada, SMP TP 45 Sukasada, SMP Maulana Pegayaman, MTs. Al-Iman Pegayaman dan Mts. Tegal Linggah.

Guru-guru IPA yang mengajar di SMP ini berlatar belakang pendidikan Fisika dan Biologi. Pembelajaran yang dilakukan oleh guru-guru IPA SMP lebih mengarah pada pembelajaran langsung yang berpusat pada guru (teacher centered). Mereka kurang memiliki pemahaman yang mendalam terhadap pembelajaran inovatif yang berkembang saat ini sehingga mereka kurang mampu untuk menerapkan pembelajaran yang interaktif, inspiratif, menyenangkan, menantang, dan memotivasi siswa untuk berpartisipasi aktif, serta memberikan ruang yang cukup bagi prakarsa, kreativitas, dan kemandirian sesuai dengan bakat, minat, dan perkembangan fisik serta psikologis peserta didik. Mereka kurang memiliki pemahaman dalam menerapkan atau mengembangkan model-model pembelajaran inovatif, misalnya model pembelajaran berbasis budaya lokal (Bali). Pembelajaran atau praktikum berbasis budaya lokal (Bali) 
telah banyak dilakukan dan terbukti efektif dalam meningkatkan hasil belajar siswa (Suja, et al., 2007; Suastra, el al., 2011 ) dan keterampilan berpikir kritis siswa/ mahasiswa (Selamat, et al., 2009; Suardana, 2010).

Perangkat pembelajaran yang dibuat oleh guru-guru IPA cenderung menonton dan tidak memasukkan aspek budaya lokal. Rencana pelaksaaan pembelajaran yang dibuat sudah mengacu pada Permen RI No. 41 tahun 2007 tentang standar proses, tetapi rumusan tujuan belum menunjukkan proses yang jelas untuk pencapaian hasil belajar serta tahapan pembelajaran tidak runut dan kurang jelas. Hal senada juga ditemukan Suastra (2010) bahwa 90\% guru menyatakan berkeinginan untuk mengembangkan model pembelajaran sains berbasis budaya lokal, namun hanya $20 \%$ guru yang memiliki wawasan/pengetahuan dan ke-mampuan untuk mengembangkannya. Ini mengindikasikan bahwa model pembelajaran berbasis budaya lokal dapat diterima dengan baik, meskipun wawasan dan pengetahuan mereka masih minim. Minimnya wawasan/pengetahuan guru terhadap model pembelajaran sains berbasis budaya terletak pada kurangnya kemampuan guru dalam mencari contoh-contoh kejadian/peristiwa yang mengandung nilai kearifan lokal untuk dapat diintegrasikan ke dalam silabus atau rencana pelaksanaan pembelajaran (RPP).

Temuan penelitian lainnya menunjukkan bahwa guru-guru IPA SMP masih mengalami kesulitan dalam mengajarkan sains kimia dan mengganggap materi sains kimia terlalu luas dan tidak sistematis (Suja, et al., 2007). Selain itu, guru-guru IPA SMP juga belum memahami sains asli (budaya lokal) yang dapat diintegrasikan ke dalam pembelajaran, walaupun sesungguhnya tanpa disadari mereka telah menyinggungnya dalam pembelajaran aspek kimia yang sedang diajarkannya. Misalnya, penggunaan garam dapur untuk pengawetan ikan sering dilakukan dalam pembelajaran, tetapi mereka tidak secara eksplisit memasukkan dalam RPP.

Lebih lanjut, hasil diskusi penulis dengan beberapa guru IPA SMP di Kecamatan Sukasada terungkap bahwa mereka belum memiliki pemahaman berkaitan dengan budaya Bali yang dapat diintegrasikan dalam pembelajaran IPA. Dalam pembelajaran IPA, mereka berpedoman pada buku-buku dan LKS yang ada. Mereka belum mengaitkan pembelajaran yang dilakukan dengan budaya lokal yang berkembang di masyarakat. Di samping itu, guru-gusu IPA SMPA ini juga belum memahami 
pembelajaran berbasis budaya lokal, khususnya budaya Bali dan bagaimana penyususnan perangkat pembelajarannya. Mereka belum menyadari bahwa adanya keterkaitan antara budaya Bali dengan pembelajaran IPA. Mereka juga menyatakan bahwa untuk praktikum IPA, khususnya sains kimia, sangat jarang bisa dilakukan karena keterbatasan waktu yang tersedia dan tidak adanya tenaga laboran.

Berdasarkan uraian di atas, rumusan masalah yang dicarikan solusinya melalui kegiatan pengabdian kepada masyarakat ini adalah sebagai berikut. (1) Apakah kegiatan P2M ini dapat meningkatkan pemahaman guru-guru IPA SMP di Kecamatan Sukasada tentang budaya Bali yang relevan dengan sains kimia SMP? (2) Apakah kegiatan P2M ini dapat meningkatkan pemahaman guru-guru IPA SMP di Kecamatan Sukasada tentang pembelajaran berbasis budaya Bali? (3) Apakah kegiatan P2M ini dapat meningkatkan pemahaman dan keterampilan guru-guru IPA SMP di Kecamatan Sukasada dalam menyusun perangkat pembelajaran berbasis budaya Bali?, dan (4) Bagaimanakah respon guru-guru IPA SMP di Kecamatan Sukasada terhadap kegiatan $\mathrm{P} 2 \mathrm{M}$ ini?

\section{Metode Pelaksanaan Pengabdian}

Sasaran kegiatan P2M ini adalah guru-guru IPA SMP di Kecamatan Sukasada. Metode yang digunakan untuk mencapai tujuan yang telah dirumuskan di depan adalah metode ceramah, diskusi, dan pelatihan yang dilaksanakan dalam bentuk seminar dan pelatihan. Keterkaitan antara tujuan, metode, dan bentuk kegiatan P2M ini disajikan pada Tabel 1.

Tabel 1. Keterkaitan Tujuan, Metode, dan Bentuk Kegiatan P2M

\begin{tabular}{|c|l|l|l|}
\hline No. & \multicolumn{1}{|c|}{ Tujuan } & \multicolumn{1}{|c|}{ Metode } & \multicolumn{1}{|c|}{$\begin{array}{c}\text { Bentuk } \\
\text { Kegiatan }\end{array}$} \\
\hline 1. & $\begin{array}{l}\text { Meningkatkan pemahaman guru-guru IPA } \\
\text { SMP di Kecamatan Sukasada tentang budaya } \\
\text { Bali yang relevan dengan sains kimia. }\end{array}$ & $\begin{array}{l}\text { Ceramah dan } \\
\text { diskusi }\end{array}$ & Seminar \\
\hline 2. & $\begin{array}{l}\text { Meningkatkan pemahaman guru-guru IPA } \\
\text { SMP di Kecamatan Sukasada tentang } \\
\text { pembelajaran berbasis budaya Bali }\end{array}$ & $\begin{array}{l}\text { Ceramah dan } \\
\text { diskusi }\end{array}$ & Seminar \\
\hline 3. & $\begin{array}{l}\text { Meningkatkan pemahaman dan keterampilan } \\
\text { guru-guru IPA SMP di Kecamatan Sukasada } \\
\text { dalam menyusun perangkat pembelajaran } \\
\text { sains kimia berbasis budaya Bali. }\end{array}$ & $\begin{array}{l}\text { Diskusi dan } \\
\text { Pelatihan }\end{array}$ & $\begin{array}{l}\text { Seminar dan } \\
\text { pelatihan }\end{array}$ \\
\hline
\end{tabular}


Seminar dan pelatihan penyusunan perangkat perangkat pembelajaran sains kimia berbasis budaya Bali diselenggarakan di Ruang Sidang FMIPA Universitas Pendidikan Ganesha dengan melibatkan guru-guru IPA SMP di Kecamatan Sukasada. Untuk mengetahui keberhasilan kegiatan P2M ini dilakukan evaluasi terhadap proses dan produk kegiatan serta respon guru-guru yang terlibat dalam seminar dan pelatihan. Evaluasi proses berkaitan dengan partisipasi guru-guru dalam diskusi (mengajukan atau menjawab pertanyaan), semangat mengikuti kegiatan, dan kerja sama. Evaluasi proses dilakukan selama kegiatan berlangsung. Evaluasi produk dilakukan terhadap kualitas perangkat pembejaran berbasis budaya Bali yang dihasilkan sebagai produk lokakarya. Perangkat pembelajaran yang dibuat meliputi: Silabus, Rencana Pelaksanaan Pembelajaran (RPP) dan Lembar Kerja Siswa (LKS). Sementara itu, respon guru-guru dijaring melalui angket.

\section{Hasil dan Pembahasan}

Kegiatan P2M ini dilakukan melalui seminar dan pelatihan pembuatan perangkat pembelajaran sains kimia berbasis budaya Bali bagi guru-guru IPA SMP di Kecamatan Sukasada. Seminar dan pelatihan dilaksanakan pada hari Rabu, 6 Nopember 2013 bertempat di Ruang Sidang FMIPA UNDIKSHA. Seminar dan pelatihan dibuka oleh Sekretaris Lembaga Pengabdian kepada Masyarakat (LPM) Dr. I Wayan Mudana, M.Si., selaku perwakilan dari Ketua LPM. Nara sumber dalam kegiatan ini adalah Dr. I Nyoman Suardana, M.Si. dari Jurusan Pendidikan Kimia FMIPA UNDIKSHA. Dalam kegiatan pelatihan penyusunan perangkat pembelajaran nara sumber dibantu oleh dua tenaga pembimbing, yaitu: Dr. I Dewa Ketut Sastrawidana, S.Si., M.Si. dan Drs. Nyoman Retug, M.Si. Seminar dan pelatihan ini dihadiri oleh 11 peserta, yang terdiri atas 8 guru IPA SMP di Kecamatan Sukasada dan 3 mahasiswa Jurusan Pendidikan Kimia FMIPA UNDIKSHA. Jumlah keseluruhan undangan sebanyak 24 orang. Peserta kegiatan seminar dan pelatihan ini disajikan pada Tabel 1

Tabel 1 Peserta yang Hadir dalam Seminar dan Pelatihan

\begin{tabular}{|c|l|c|}
\hline No & \multicolumn{1}{|c|}{ Nama } & Lembaga \\
\hline 1 & Made Astrini & SMP TP 45 Sukasada \\
\hline 2 & Ketut Masah & SMP Negeri 2 Sukasada \\
\hline 3 & Nyoman Sri Ardana, S.Pd. & SMP Negeri 2 Sukasada \\
\hline
\end{tabular}




\begin{tabular}{|c|l|c|}
\hline 4 & Ni Made Widiastini, S.Pd. & SMP Negeri 4 Sukasada \\
\hline 5 & Gede Sucita, S.Pd. Bio. & SMP Negeri 4 Sukasada \\
\hline 6 & I Made Budiyasa & SMP Negeri 4 Sukasada \\
\hline 7 & I Nengah Rapet, S.Pd. & SMP Maulana Pegayaman \\
\hline 8 & Hafifah & MTs. Al-Iman Pegayaman \\
\hline 9 & I G Agung Sandy Satriawan & Universitas Pendidikan Ganesha \\
\hline 10 & Vicky Enggy Caudea Indra E & Universitas Pendidikan Ganesha \\
\hline 11 & Putu Sista Dharmika & Universitas Pendidikan Ganesha \\
\hline
\end{tabular}

Guru-guru IPA SMP yang hadir dalam kegiatan seminar dan pelatihan sebagian besar berlatar belakang Pendidikan Fisika dan Biologi, tidak ada yang berlatar belakang Pendidikan Kimia. Hal ini menunjukkan bahwa guru-guru IPA SMP di Kecamatan Sukasada tidak memiliki latar belakang pendidikan yang berimbang antara Pendidikan Kimia, Fisika, dan Biologi. Di samping itu, guru-guru IPA SMP di Kecamatan Sukasada tidak ada yang berpendidikan IPA. Kegiatan seminar dan pelatihan berlangsung dari jam 08.00 Wita s/d 16.00 WITA

Seminar dan pelatihan berlangsung baik dan lancar. Kegiatan seminar dan pelatihan mendapat sambutan positif dari guru dan mahasiswa yang hadir. Guru-guru IPA SMP dan mahasiswa sangat antosias mengikuti kegiatan seminar dan pelatihan. Mereka banyak yang bertanya tentang budaya Bali, misalnya apakah budaya Bali yang tidak dikenali oleh siswa akan dapat berpengaruh positif terhadap pembelajaran yang dilakukan? Mereka juga menanyakan bagaimana usaha kita untuk memendung budaya Barat agar budaya Bali tidak punah? Pada bagian mana dari silabus atau RPP, budaya Bali dapat diintegrasikan? Pertanyaan yang dijukan ini menunjukkan bahwa guru-guru secara sungguh-sungguh mengikuti kegiatan seminar dan pelatihan agar mereka memperoleh manfaat dari kegiatan ini.

Dalam kegiatan pelatihan, mereka juga dapat bekerja sama dengan baik dalam menysusun perangkat pembelajaran. Perangkat pembelajaran yang disusun berupa Silabus, Rencana Pelaksanaan Pembelajaran (RPP) dan Lembar Kerja Siswa (LKS) berbasis budaya Bali. Secara umum perangkat yang susun oleh guru-guru sudah baik. Perangkat yang dibuat oleh guru tersebut sudah menunjukkan adanya relevansi antara budaya Bali dan kompetensi dasar atau indikator pencapaian kompetensi. Namun, rumusan idikator dan tujuan tidak relevan, disamping itu tujuan yang dirumuskan hanya menyatakan hasil dan tidak disertai proses untuk pencapaian hasil tersebut. Misalnya, 
rumusan tujuan: siswa dapat menjelaskan prinsip pemisahan campuran. Kegiatan pembelajaran juga masih ditemukan belum adanya kesesuaian antara model yang digunakan dengan langkah-langkah pembelajaran dan kegiatan pada langkah eksplorasi guru menjelaskan materi pelajaran. Di samping itu, penilaian juga belum semuanya sesuai dengan indikator pencapaian kompetensi.

Walaupun masih terdapat kelemahan dalam perangkat pembelajaran yang dibuat oleh guru-guru sains SMP, tetapi secara umum perangkat yang dibuat sudah baik. Hal ini menunjukan terjadi peningkatan pemahaman dan keterampilan guru-guru IPA dalam membuat perangkat pembelajaran sains kimia berbasis budaya Bali. Secara ringkas hasil kegiatan seminar dan pelatihan ini disajikan pada Tabel 2.

Tabel 2. Hasil Kegiatan Seminar dan Pelatihan

\begin{tabular}{|l|l|l|l|}
\hline No & Kegiatan & \multicolumn{1}{|c|}{ Sasaran } & \multicolumn{1}{c|}{ Hasil } \\
\hline 1 & Seminar & $\begin{array}{l}\text { Guru-guru IPA SMP di } \\
\text { Kecamatan Sukasada }\end{array}$ & $\begin{array}{l}\text { Meningkatkan pemahaman guru-guru IPA } \\
\text { SMP tentang budaya Bali yang relevan dengan } \\
\text { sains kimia SMP, pembelajaran berbasis } \\
\text { budaya lokal Bali, dan perangkat pembelajaran } \\
\text { sains kimia berbasis budaya Bali }\end{array}$ \\
\hline 2 & Pelatihan & $\begin{array}{l}\text { Guru-guru IPA SMP di } \\
\text { Kecamatan Sukasada }\end{array}$ & $\begin{array}{l}\text { Meningkatkan pemahaman dan keterampilan } \\
\text { guru-guru IPA SMP dalam menyusun } \\
\text { perangkat pembelajaran sains kimia berbasis } \\
\text { budaya Bali }\end{array}$ \\
\hline
\end{tabular}

Seminar dan pelatihan ini mendapat respon positif dari guru-guru IPA SMP yang terlibat dalam kegiatan tersebut. Respon guru-guru terhadap seminar dan pelatihan disajikan pada Tabel 3.

Tabel 3 Respon Guru terhadap Seminar dan Pelatihan

\begin{tabular}{|c|l|c|c|c|c|}
\hline \multirow{2}{*}{ No } & \multicolumn{1}{|c|}{ Pertanyaan } & \multicolumn{4}{|c|}{ Respon (\%) } \\
\cline { 3 - 6 } 1 & SS & S & TS & STS \\
\hline \multirow{2}{*}{2} & $\begin{array}{l}\text { Setelah saya mengikuti seminar dan pelatihan, saya lebih } \\
\text { memahami budaya Bali yang dapat diintegrasikan dalam } \\
\text { pembelajaran sains kimia }\end{array}$ & 50,0 & 50,0 & - & - \\
\hline & $\begin{array}{l}\text { Setelah mengikuti seminar dan pelatihan, pengetahuan dan } \\
\text { keterampilan saya bertambah tentang penyusunan perangkat } \\
\text { pembelajaran berbasis budaya Bali }\end{array}$ & 62,5 & 37,5 & - & - \\
\hline 3 & $\begin{array}{l}\text { Setelah mengikuti seminar dan pelatihan, kepercayaan diri } \\
\text { saya bertambah dalam menyusun perangkat pembelajaran } \\
\text { berbasis budaya Bali }\end{array}$ & 25,0 & 75,0 & - & - \\
\hline 4 & Setelah mengikuti pelatihan, saya termotivasi untuk & 62,5 & 37,5 & - & - \\
\hline
\end{tabular}




\begin{tabular}{|c|l|c|c|c|c|}
\hline & menerapkan pembelajaran berbasis budaya Bali & & & & \\
\hline 5 & $\begin{array}{l}\text { Seminar dan pelatihan yang saya ikuti telah menyadarkan } \\
\text { saya akan kekurangan/kelebihan saya dalam penyusunan } \\
\text { perangkat pembelajaran }\end{array}$ & 87,5 & 12,5 & - & - \\
\hline 6 & $\begin{array}{l}\text { Seminar dan pelatihan yang saya ikuti telah menginspirasi } \\
\text { saya untuk menjadi guru yang lebih kreatif dan inovatif }\end{array}$ & 37,5 & 62,5 & - & - \\
\hline 7 & $\begin{array}{l}\text { Seminar dan pelatihan yang saya ikuti telah meningkatkan } \\
\text { motivasi saya untuk meningkatkan kompetensi saya }\end{array}$ & 37,5 & 62,5 & - & - \\
\hline & Rerata & 51,8 & 48,2 & - & - \\
\hline
\end{tabular}

Dari angket terbuka, guru menyatakan bahwa pelaksanaan seminar dan pelatihan sudah berlangsung sangat baik dan sangat bermanfaat untuk meningkatkan kompetensi mereka, tetapi mereka menyayangkan banyak guru-guru tidak dapat hadir mengikuti kegiatan ini. Guru berharap agar program ini dilakukan secara berkesinambungan dan dilanjutkan sampai praktek pembelajarannya sehingga pengetahuan dan keterampilan mereka lebih mendalam. Di samping itu, guru-guru juga menyarankan agar dapat dilakukan seminar dan pelatihan tentang: 1) Kurikulum 2013, dan 2) pembuatan media pembelajaran. Dengan kegiatan pelatihan ini, guru lebih memahami pembelajaran berbasis budaya lokal dan dapat meningkatkan motivasi mereka untuk menjadi guru yang lebih kreatif dan inovatif.

Berdasarkan kegiatan seminar dan pelatihan yang telah diuraikan di atas, nampak bahwa terjadi peningkatan wawasan dan pemahaman guru-guru IPA SMP di Kecamatan Sukasada tentang budaya Bali yang relevan dengan sains kimia SMP dan pembelajaran berbasis budaya lokal Bali serta peningkatan pemhaman dan keterampilan guru-guru IPA dalam pembuatan perangkat pembelajaran sains kimia berbasis budaya Bali, khususnya silabus, RPP, dan LKS berbasis budaya Bali.

\section{Penutup}

Berdasarkan hasil dan pembahasan di atas maka dapat disimpulkan sebagai berikut. 1) Kegiatan P2M dapat meningkatkan pemahaman guru-guru IPA SMP di Kecamatan Sukasada tentang budaya Bali yang relevan dengan sains kimia SMP. 2) Kegiatan P2M dapat meningkatkan pemahaman guru-guru IPA SMP di Kecamatan Sukasada tentang pembelajaran berbasis budaya lokal. 3) Kegiatan P2M dapat meningkatkan pemahaman dan keterampilan guru-guru IPA SMP dalam penyusunan perangkat pembelajaran sains 
kimia berbasis budaya Bali. 4) Guru-guru IPA SMP di Kecamatan Sukasada memberikan respon positif terhadap pelaksanaan P2M ini.

Guru-guru IPA SMP diharapkan dapat menyempurnakan perangkat pembelajaran yang telah dibuat dalam pelatihan dan menerapkannya dalam pembelajaran serta dikembangkan lebih lanjut untuk topik-topik yang lain. Bagi para pelaksana kegiatan P2M, model seminar dan pelatihan seperti ini perlu dilakukan juga dilakukan terhadap guru-guru IPA SMP di kecamatan atau daerah lain sehingga pembelajaran berbasis budaya lokal menjadi salah satu upaya untuk meningkatkan hasil belajar siswa dan dapat memperkuat atau melestarikan budaya lokal.

\section{DAFTAR PUSTAKA}

Badan Standar Nasional Pendidikan. (2006). Panduan Penyusunan Kurikulum Tingkat Satuan Pendidikan Jenjang Pendidikan Dasar dan Menengah. Jakarta: BSNP.

Selamat, I N., Redhana, I W., \& Suardana, I N. (2009). Pengembangan Buku Kerja Kimia Berbasis Peta Argumen Menggunakan Konteks Budaya Lokal untuk Meningkatkan Keterampilan Berpikir Kritis Siswa SMA. Laporan Penelitian Undiksha Tidak Dipublikasikan.

Suardana, I N. (2010). Pengembangan Model Praktikum Kimia Dasar Berbasis Budaya Bali untuk Meningkatkan Keterampilan Berpikir Kritis Mahasiswa Calon Guru Kimia. Disertasi SPs UPI Tidak Dipublikasikan.

Suastra, I W. (2010). Model Pembelajaran Sains Berbasis Budaya Lokal untuk Mengembangkan Kompetensi Dasar Sains dan Nilai Kearifan Lokal di SMP. Jurnal Pendidikan dan Pengajaran. 43(2). 8-16.

Suastra, I W., Tika, K., \& Kariasa, N. (2011). Efektivitas Model Pembelajaran Sains Berbasis Budaya Lokal untuk Mengembangkan Kompetensi Dasar Sains dan Nilai Kearifan Lokal Di SMP. Jurnal Penelitian dan Pengembangan. 5(3), 258-273.

Suja, I W., Sudria IBN., \& Muderawan, I W. (2007). Integrasi Sains Asli (Indigeneous Science) ke dalam Kurikulum Sains Sekolah sebagai Upaya Pengembangan Pendidikan Sains Berbasis Content dan Context Budaya Bali. Laporan Penelitian. Tidak Diterbitkan. 